\title{
Gold Films for the Control and Utilisation of Radiant Energy
}

\author{
R. C. Langley \\ Engelhard Industries, Menlo Park, New Jersey \\ The method of preparing thin films-about 500 to 2000 A thick-by \\ thermal decomposition of organometallic compounds has been applied \\ to produce gold films useful as reflectors or as selective absorbers of \\ radiant energy. In either case the gold films deposited on metallic \\ substrates are stabilised by an intermediate diffusion barrier of \\ refractory oxide which permits operation at elevated temperatures.
}

The conversion of radiant energy from the sun into usable heat is becoming of increasing importance as a means of economising in the consumption of other non-replaceable fuels.

Gold or gold-containing materials can be obtained with optical properties which make them uniquely useful for this energy conversion. Gold-coated surfaces can be used in reflectors to concentrate radiant energy on to the surfaces to be heated under conditions in which the reflecting surface itself attains high temperatures. Gold can also be employed in collectors for solar energy. The parameters for the latter application may be described as follows.

For the absorption of solar radiation special materials are required having a combination of optical properties. The term "selective absorbers" has come into general use for these materials, which are usually applied in the form of a coating on to the heat transfer surfaces. A physical theory for actual or suggested selective absorbers has been presented in the literature (1).

An efficient absorber material must absorb most of the energy in the wavelength band of 0.3 to 2.0 microns. This is the band which contains almost all solar energy which reaches the surface of the earth. Absorption of this energy is easily achieved with common materials; for example, carbon black or a carefully prepared oxide coating on Inconel are excellent absorbers of radiant energy in this band. However, these materials are also excellent emitters (re-radiators) at wavelengths in the band of 2.0 to 10.0 microns. As a result, when heated by solar radiation these materials emit in the near infra-red and the net result is that their equilibrium temperature is low.

Materials which have very low emissivity in the band of 2.0 to 10.0 microns are those metals which have the lowest electrical resistivity. These are aluminium, copper, silver and gold; their emissivity is at a minimum in this band when the metals are completely dense and have highly polished surfaces which are free of any substantial oxide coating. However, these materials of low emissivity are very poor absorbers in the band of 0.3 to 2.0 microns. Two of them, aluminium and silver, are so highly reflective of energy in this band that they find use as standards for reflection. The other two, copper and gold, absorb slightly in this band but their reflectivity is still very high.

The apparent paradox of an absorber material which combines high absorptance of solar radiation (high alpha) and low total hemispherical emittance (low epsilon) has been resolved by other workers in various ways. The solar absorptance of smooth, low emittance materials (metals) has been significantly increased by forming the metal with deep corrugations so that incident radiation undergoes more than one reflection. This has been the subject of a patent (2).

Another approach is to coat a polished metal base with a thin layer of a material which absorbs solar radiation and which is transparent at wavelengths longer than 2.0 microns. The absorbing layer might be one or several dielectric interference films on aluminium (3), or a carefully controlled thickness of copper oxide on copper (4). In this case the oxide film is grown by controlled immersion in an oxidising bath. Because of the simplicity of their preparation, selective absorbers of this type have had wide use in Australia as coatings on water heater collector plates.

Still another approach is to coat a polished metal with a substantial thickness of a semiconductor. Some semiconductor materials are opaque in the wavelength band of 0.3 to 2.0 microns but are so transparent in the wavelength band of 2.0 to 10.0 microns that they find use as lenses in infra-red optical instruments. Another approach uses chemical vapour deposition to apply silicon over a mirror film of silver to achieve selective absorption (5). 
The high reflectivity and low emissivity of gold, together with its complete freedom from tarnishing, are finding a number of applications in the control of radiant energy, ranging from the concentration of solar energy to the improvement of the efficiency of electric cookers. To reduce overheating in fighter aircraft, stainless steel heat shields coated with a gold film are fitted over the jet pipes and effectively reduce radiation from the hot jet stream

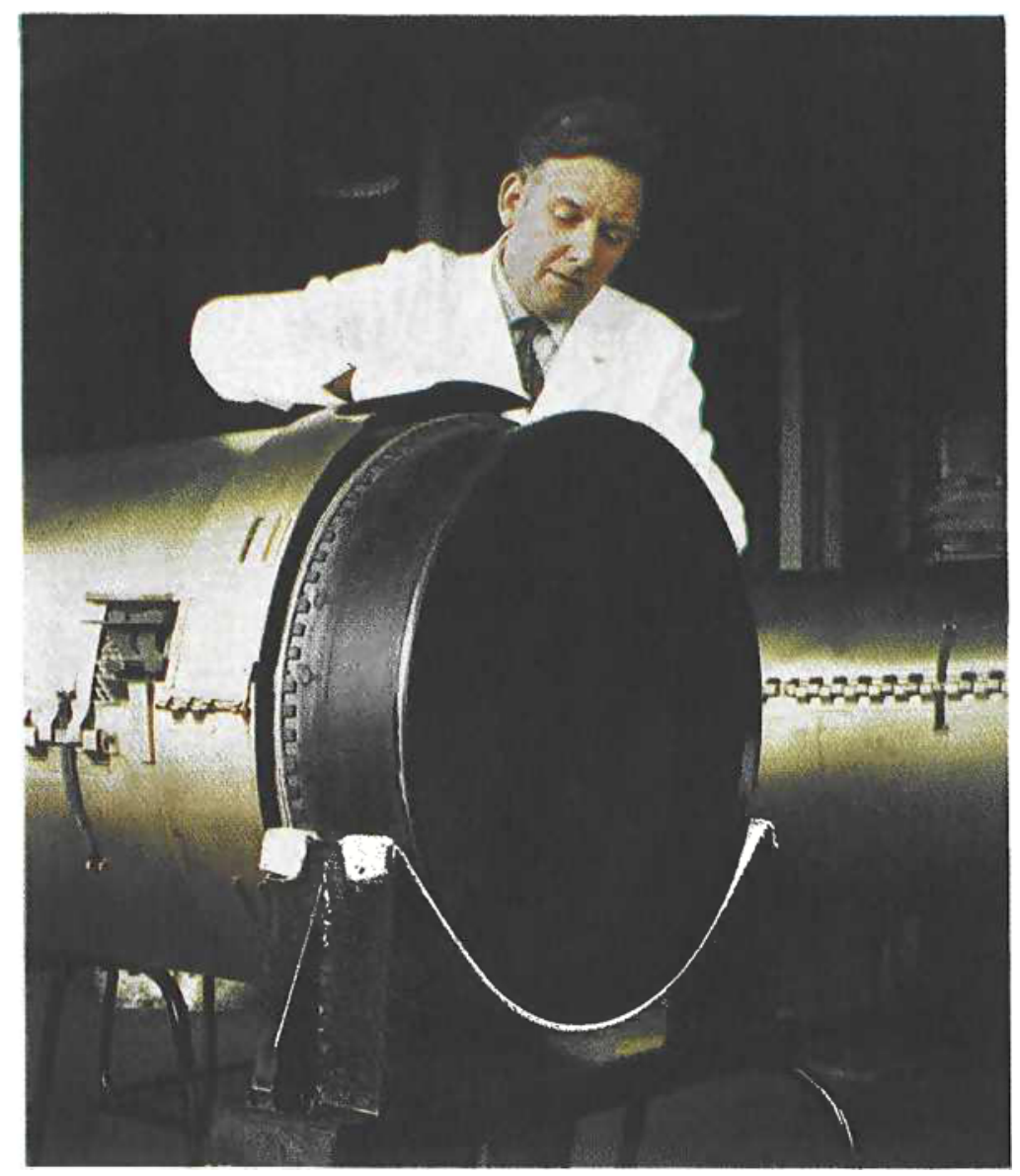

There is a need to increase the operating temperature of solar energy absorbers to permit utilisation of solar energy for applications such as generation of high pressure steam. Gold, having low emissivity and being resistant to tarnishing, appears particularly suitable for this service. However, it would be necessary to incorporate modifiers into gold which would change its characteristics of low absorbance so that gold would become an effective selective absorber. This has been achieved by preparing gold films via the organometallic route. A brief account of this development has been included in an earlier paper by the author in this journal (6).

In the following, the use of organometallic compounds is discussed for preparing thin films, and the specifics of gold films developed for use as reflectors or as selective absorbers of solar energy are more fully described.

\section{Films from Organometallic Compounds}

Historically, thin film technology originated with the development of gold films. For the surface decoration of ceramics, gold applied in powder form has been used for hundreds of years and the technique is still essentially the same in use today. These films are designated as thick film in distinction from thin films prepared from organometallic compounds. Thick gold films are of the order of 25 microns thick whereas the thickness of thin films usually is in the range from 500 to 2000 Angstroms. An important technological use of thick gold films is in microelectronics which has recently been discussed in this journal by Finch (7).

Starting in about 1800, European porcelain manufacturers tried to develop a process to reduce the cost of decorating with gold. Their aim was to apply the metal in much thinner coatings than was possible using the powder method. A second goal was to have the gold coating fired on the ceramic with a mirror finish to eliminate hand polishing, necessary with the older technique. By 1830, both goals were realised. The Royal Porcelain Factory at Meissen perfected a process which remained a closely guarded secret until 1851. In this process mirror films of gold, about 1000 Ångstroms in thickness, were obtained on porcelain without polishing.

The process became public in 1851 when a French manufacturer received a patent on what was essentially the earlier German process. The patent disclosed the use of a particular organic gold compound, applied from solution and thermally decomposed in air. The manufacture of the compound 


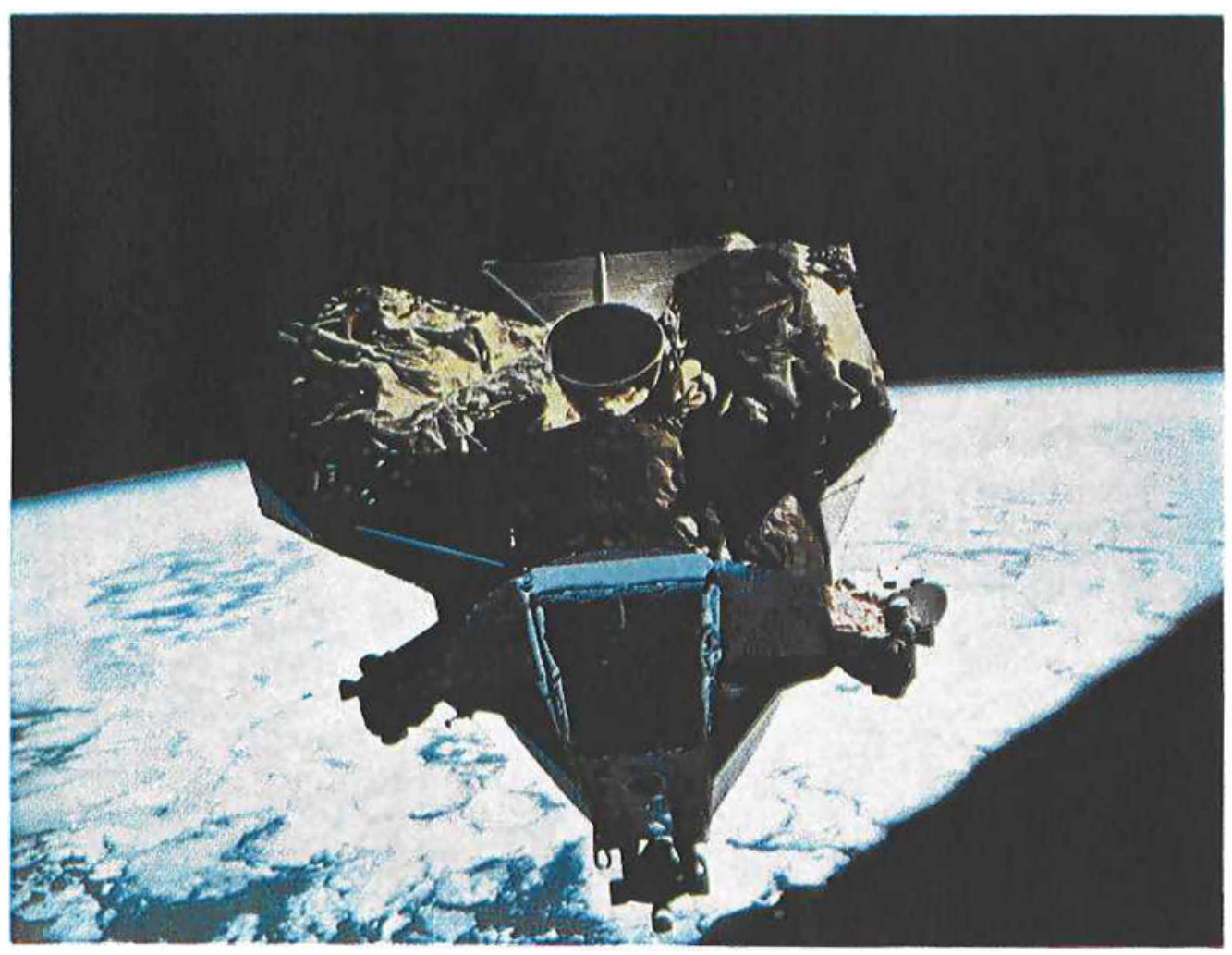

The problems involved in space travel provided a further incentive to the development of gold films suitable to withstand the extreme conditions of radiation to be encountered. A reflective gold film on a plastic foil was used to protect the Lunar Modules from the intemse solar radiation in the airless conditions of space

was described in detail and it was governed by these considerations:

(1) High solubility in organic solvents is necessary to obtain a reasonable weight of metal in solution.

(2) The compound must not sublime, even at elevated temperature.

(3) At their decomposition temperature, the organics must volatilise completely to leave a pure metal film.

These requirements were met using terpenes as the starting organic material, and reacting them to form gold terpene sulphides as the organometallic product. The starting terpenes were not pure but consisted of a variety of compounds of natural origin. Terpenes are the principal constituents of turpentine and are subject to wide chemical and structural variations depending on the source of the oil. Even today they are difficult to isolate as pure compounds, and in practice turpentine from particular sources was found to work well and was used without purification.

In the manufacturing method described by the French firm, the terpenes are treated with elemental sulphur to give terpene sulphides. This intermediate is then reacted with gold chloride to give the final product, which is soluble in turpentine to the extent that 24 per cent gold by weight is obtained in solution. These compounds are not volatile and decompose at about $250^{\circ} \mathrm{C}$ to leave pure gold deposits.
The 1851 process remained essentially unchanged in a chemical sense for more than 100 years. It was, however, extended to make similar organic compounds of platinum, palladium, rhodium, and silver, and these compounds have had long commercial use despite the uncertain chemistry of the natural products used as starting materials.

\section{Development of Organometallic Compounds}

About 15 years ago research at Engelhard was directed to new organic gold compounds made from starting materials of high purity, and not of terpene origin. Alkyl mercaptans were selected as starting materials since they can be made from propylene, a common chemical made from crude oil and available im high purity. A number of alkyl mercaptans were treated with gold chloride to give gold alkyl mercaptides of high purity $(8,9,10)$. Most of these compounds are insoluble, but certain of the tertiary isomers have unusually high solubility. A compound such as the one shown below has proved very useful im this process.

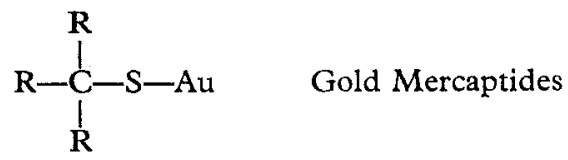


When an alkyl gold mercaptide has the structure shown, that is the functional carbon is joined to other carbons and not to hydrogen, the compound is very soluble. The preferred compound of this structure has 12 carbon atoms. It is a solid containing 49 per cent gold but it is so soluble that 35 per cent gold can be obtained in solution in toluene. By contrast, the normal isomer, a straight chain compound without the high degree of branching shown here, is essentially insoluble. Gold tertiary dodecyl mercaptide decomposes at $150^{\circ} \mathrm{C}$ and this property allows many thermally sensitive materials to be gold coated by this method.

Thus far, gold has been emphasised as the metal. In the structure shown, silver can be used instead of gold to give equally useful compounds. In this research, other silver compounds were investigated and a useful class proved to be silver carboxylates, as shown below and described in reference (11).<smiles>[Y19]OC(=O)C([R])([R])[R]</smiles>

This structure is drawn to indicate that the molecule is highly branched and this is necessary to obtain high solubility. The silver atom can be replaced by copper to give another useful class of compounds.
Two other classes of compounds are shown below. These compounds contain both a silver atom and a gold atom in the same molecule. As sketched, the atoms are adjacent in these structures and thermal decomposition results in gold-silver alloys at low temperatures. Preparation and other properties of these two classes of compounds are described in a patent specification (12).

$$
\mathrm{R}-\mathrm{C}-\mathrm{S}-\mathrm{Au} . \mathrm{Ag}-\mathrm{S}-\mathrm{C}-\mathrm{R}
$$

Gold Mercaptide complexed with Silver Mercaptide<smiles>[R]CS[14CH2][AsH2]OC([R])=O</smiles>

Gold Mercaptide complexed with Silver Carboxylate

Another type of structure, an ester, is shown below; its preparation is also described in a patent specification (13).

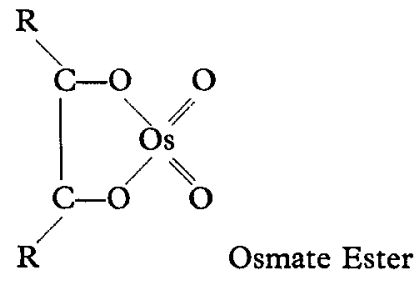

The ester term derives from use of osmic acid as the starting material; this is very volatile but when
Gold coated reflectors in this hot forming arrangement for the final sizing of steel domes for Titan rocket casings not only concentrate the heat from the high temperature quartz lamps on to the work but also prevent heat losses to the wiring and to the structure behind the reflectors

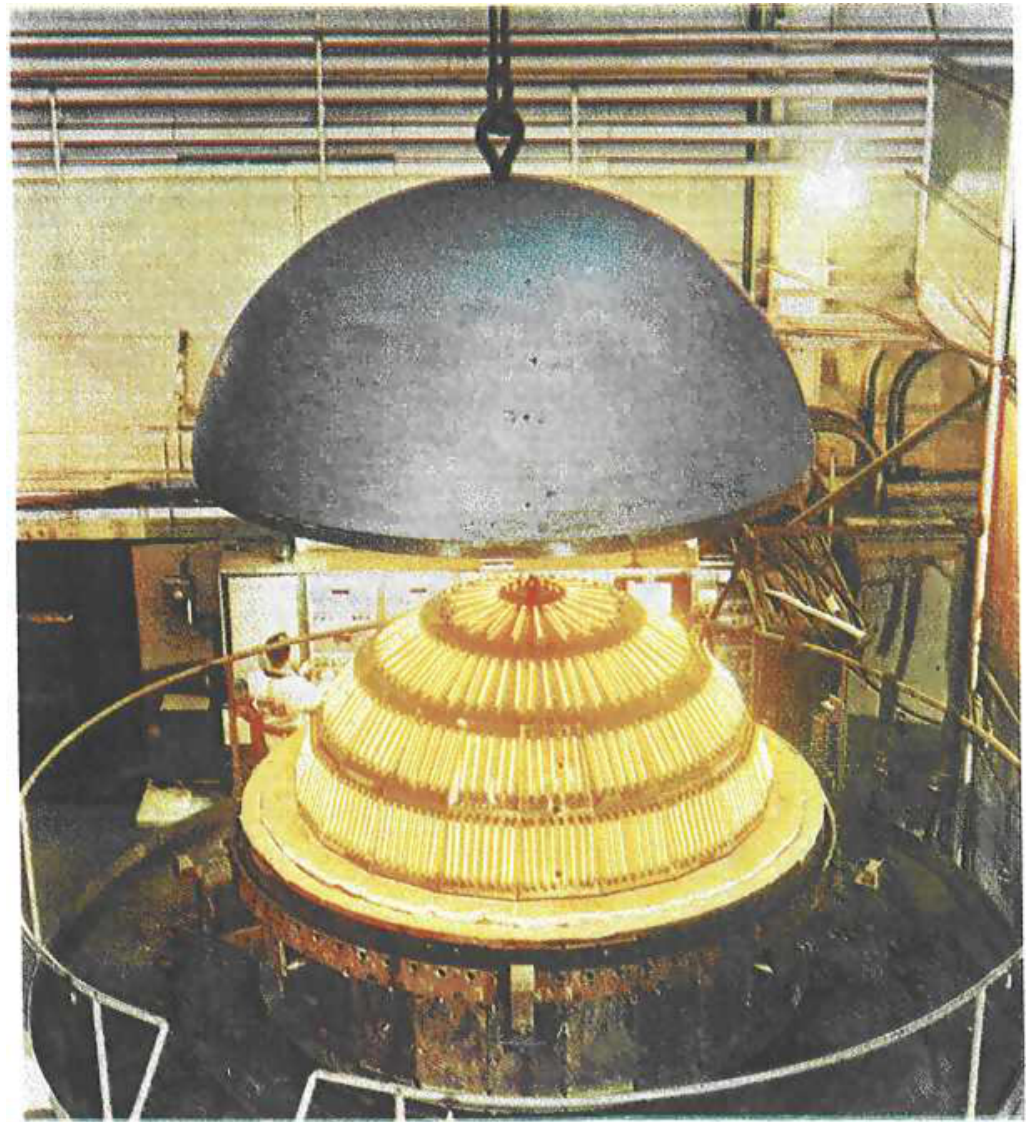


reacted with a double bond this property changes and the organometallic compound is not volatile. When total carbons present are ten, and six of them are in a ring structure, osmate esters have good solubility. In contrast to the organic compounds of other metals discussed earlier, osmium compounds must be decomposed in the absence of oxygen to prevent loss of osmium by recreating the volatile osmic acid. In this ester structure, it is possible to substitute for osmium to make another class of compounds.

Organic compounds of many other metals $(\mathbf{B i}$, $\mathrm{Pb}, \mathrm{Sn}, \mathrm{Ni}, \mathrm{Cr}, \mathrm{Fe}, \mathrm{V}, \mathrm{Si}$ as examples) are made using chemistry similar to that shown above. When fired in air, these compounds give metal oxide films which react with, and bond firmly to, ceramic and glass substrates. In making organic compounds of any metal, a consideration is that all compounds are soluble in the same solvents. This permits composite fired films of precise composition, obtained from a single application of a solution. For example, a gold solution can have as an additive an organic rhodium compound to give a ratio of one part rhodium to 1000 parts gold. When fired in air on refractory substrates (fused silica as an example) a thin gold film with an extremely homogeneous dispersion of rhodium oxide is obtained. The rhodium oxide additive imparts a striking degree of thermal stability to a thin gold film, rendering it stable for thousands of hours at $900^{\circ} \mathrm{C}$. By contrast, an equally thin gold film without the rhodium oxide additive tends to agglomerate when heated much over $300^{\circ} \mathrm{C}$. It should be emphasised that the use of minor amounts of additives to achieve thermal stability did not come from research at Engelhard. In fact, it dates to the early development of this process in 1830 .

\section{Reflector Coatings and Absorbers of Solar Energy}

For many years thin films of gold have been used only for decorative purposes; technical applications have been developed only in recent times. An example-outside the scope of this paper-are thin film electrical resistors of highly reproducible values made by the decomposition of organometallics.

\section{Reflector Coatings}

When solar or other radiant energy is to be focused to obtain a high temperature on a collecting surface, reflectors in the focusing system may also have to operate at high temperature. If we assume, for instance, $900^{\circ} \mathrm{C}$ as a reflector surface temperature, stable optical properties can be realised using a 1000 Angstrom gold film applied by this process.

Films of gold (and also of platinum or palladium) are applied to the reflector surface. The optical arrangement between the radiant energy source and the object to be heated can be such that the object is in a focal point of the reflector. The reflector might become heated by proximity of the heat source.

There are applications where a reflective surface must be applied to a metal substrate. If a reflector of this type is operated at $600^{\circ} \mathrm{C}$, thin surface coatings of gold lose their optical properties within 60 minutes, the mechanism of change being interdiffusion between the coating and the substrate. Methods of preventing diffusion between gold films and substrates such as Inconel and stainless steel have been developed (14). It was found that an extremely thin diffusion barrier, applied by the organometallic solution process, was effective in preventing diffusion at $750^{\circ} \mathrm{C}$ for times in excess of 5000 hours, the preferred diffusion barrier material being cerium oxide. Reflectors for high intensity heat equipment are made in this way. In one design of a high intensity infrared heat source the gold film and diffusion barrier can be applied to the inner concave surface of a stainless steel envelope of the source (14).

The same type of gold film is also useful for the reduction of emission. An application of interest would be, for instance, for electric cooking stoves. It is desirable to direct all energy of the flat spiralshaped electric heating elements upward to the cooking utensils and to suppress losses of energy by radiation downward. This has been accomplished by undercoating the heating elements with a bright gold composition that has been developed as a reflector coating (15). Again, a refractory oxide diffusion barrier is employed which ensures stability of the gold film in use. Appreciable power savings can be realised by the use of this coating.

\section{Selective Absorber Coatings}

Selective absorber coatings based on gold were developed in the early stages of the U.S. space program. The need was for an Inconel surface, heated by focused solar energy, to operate continuously at $800^{\circ} \mathrm{C}$. The Inconel was to serve as the hot junction of a thermoelectric power source in manned flights. This approach to producing electric power was soon abandoned due to rapid advances in fuel cell technology, but a fair degree of success in reaching the goal of a satble solar collector surface for Inconel was realised.

The approach chosen was to add novel base metals to a bright gold solution so that the film obtained upon thermal decomposition would reflect a minimum below 1.5 microns and ideally 100 per cent above this wavelength. To assemble as much preliminary information as possible, organic solutions were made of all of the elements which can be used as additives to organic gold solutions. These elements 
At the bus terminal in Newark, New Jersey, gold films on vitreous enamelled steel reflectors behind the infra-red heaters are in use in winter time to melt the snow and to increase the comfort of waiting passengers

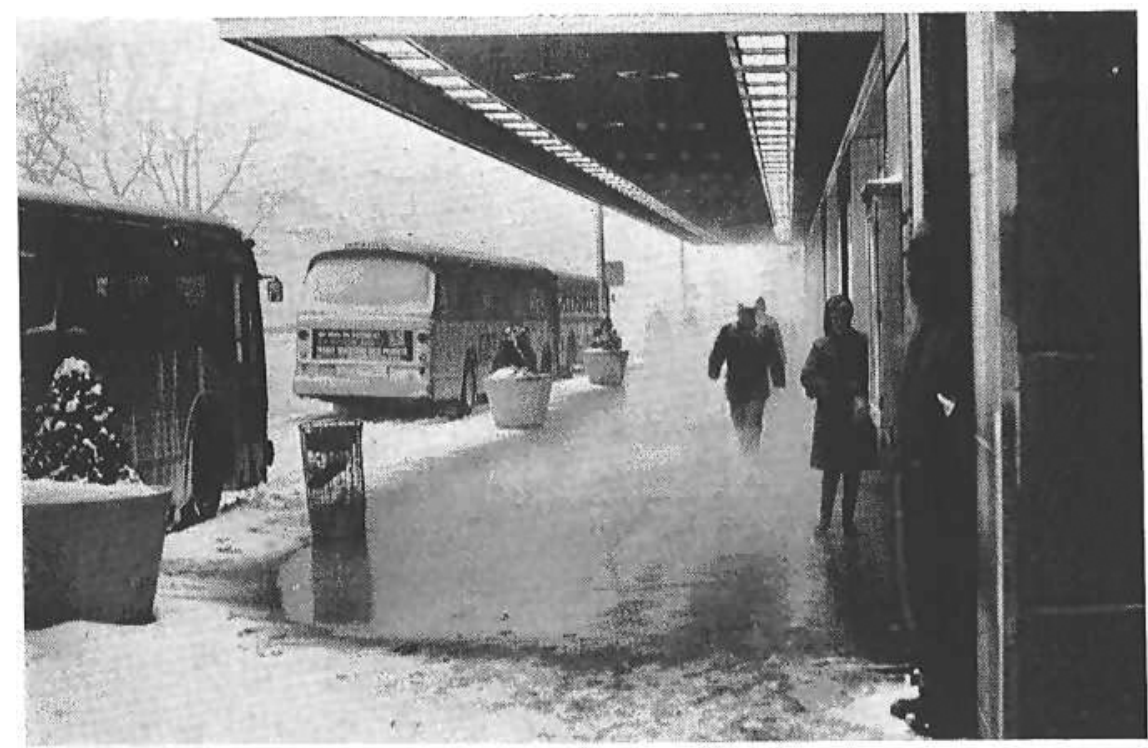

were made organic-soluble by first making the proper carboxylate, alcoholate or mercaptide. The starting acid, alcohol or mercaptan was chosen to give high solubility of the element, low volatility, complete decomposition of the organics upon heating, and compatibility with solutions of organometallic compounds generally. Solutions of the following elements were made:

$\begin{array}{lll}\text { Boron } & \text { Tantalum } & \text { Titanium } \\ \text { Cobalt } & \text { Strontium } & \text { Lanthanum } \\ \text { Silicon } & \text { Zirconium } & \text { Magnesium } \\ \text { Calcium } & \text { Cadmium } & \text { Tungsten } \\ \text { Vanadium } & \text { Tin } & \text { Germanium } \\ \text { Aluminium } & \text { Antimony } & \text { Copper } \\ \text { Lithium } & \text { Barium } & \text { Rhenium } \\ \text { Potassium } & \text { Gallium } & \text { Uranium } \\ \text { Yttrium } & \text { Neodymium } & \text { Molybdenum } \\ \text { Chromium } & \text { Praseodymium } & \text { Indium } \\ \text { Manganese } & \text { Niobium } & \text { Phosphorus } \\ \text { Iron } & \text { Cerium } & \text { Sodium } \\ \text { Nickel } & \text { Lead } & \\ \text { Zinc } & \text { Bismuth } & \end{array}$

The solutions of single base metals and some of the mixtures were then added to a gold solution in small amounts; about 5 parts base metal oxide to 95 parts gold by weight. Data obtained from reflection measurements of these films led to more complex formulations and finally to a film which partially met the goal of the work, i.e. low reflection (high absorption) at wavelengths below 1.5 microns and high reflection (low emission) above 1.5 microns.

The composition of this particular film was as follows:

\begin{tabular}{lc}
$\mathrm{Au}$ & $89.5 \%$ by weight \\
$\mathrm{Rh}_{2} \mathrm{O}_{3}$ & 0.4 \\
$\mathrm{Bi}_{2} \mathrm{O}_{3}$ & 4.5 \\
$\mathrm{Cr}_{2} \mathrm{O}_{3}$ & 0.2 \\
$\mathrm{SiO}_{2}$ & 1.7 \\
$\mathrm{BaO}$ & 3.7 \\
& $\underline{100.0}$ \\
\hline
\end{tabular}

This composite film was obtained from an organic solution containing organometallic compounds in

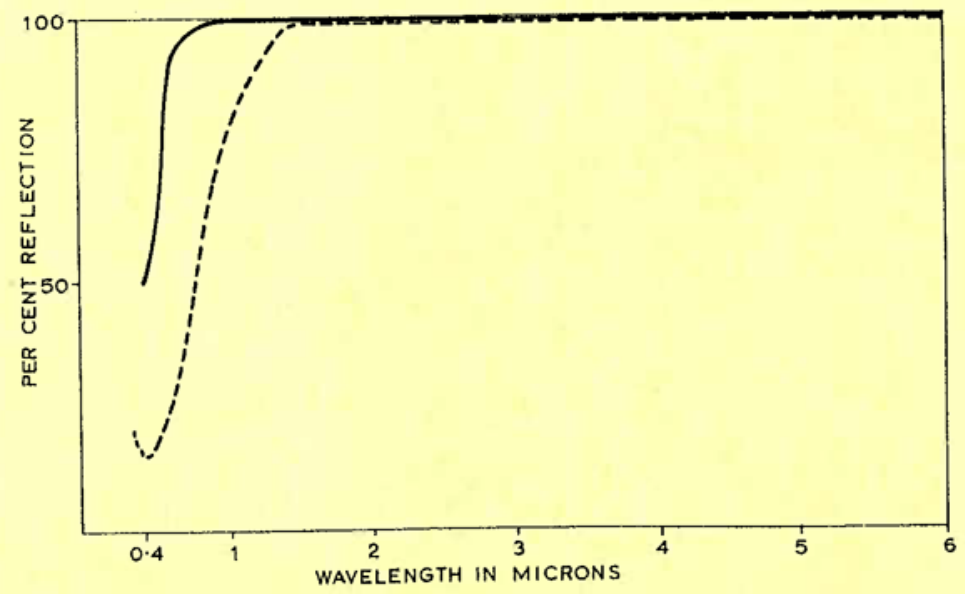

The spectral reflection of a 'pure' gold film (solid line) and a composite gold film developed as a selective solar absorber. The composite film has a minimum reflection at a wavelength of 0.5 microns, the wavelength of maximum solar radiation, while in the near infra-red it has low emissivity comparable with that of pure gold 
amounts calculated to give the above proportions after firing.

The gold film is applied to Inconel as substrate separated by a diffusion barrier of cerium oxide (16). The resulting laminate is stable at $750^{\circ} \mathrm{C}$ on Inconel for thousands of hours, both in air and in vacuum equivalent to that found in space. This is not the thermal limit of the film itself but it is the limit of the diffusion barrier material, cerium oxide.

The spectral reflection of the composite gold film is shown in the diagram, which also shows for comparison the spectral reflection of a "pure" gold film. Both films are 1000 Ångstroms thick and have zero transmission. The pure gold film has been prepared from an organometallic solution producing a conventional bright gold film. Although this film contains only 95 per cent gold-it contains among other constituents also a trace of rhodium to impart thermal stability-the measured reflectivity is in fair agreement with literature data for pure gold surfaces which have recently been reviewed by Loebich in this journal (17).

It is significant that the composite film developed as a selective solar absorber has a minimum reflection at a wavelength of 0.5 microns which is the wavelength of maximum solar radiation. In the near infra-red this film has low emissivity, essentially equal to that of pure gold.

A number of changes were made in the composition of the composite film in an effort toward ideal optical properties. Increased $\mathrm{BaO}$ or $\mathrm{SiO}_{2}$ contents were found to cause decreased reflection; increased $\mathrm{Cr}_{2} \mathrm{O}_{3}$ caused increased reflection.
The absorption maximum of the solar absorber film near 0.5 microns was further improved by use of a quarter wavelength antireflection coating of alumina. By use of an optically-interfering layer the reflectance of the energy-absorbing film underneath is materially reduced over a narrow wavelength band. Furthermore, an outer interfering layer of alumina likewise has the required thermal stability (18). This antireflection coating was also applied by the organometallic solution method.

\section{References}

1 R. M. Van Vliet, "Coatings for the Aerospace Environment", WADD Technical Report 60-773, 1961

$2 \mathrm{H}$. Tabor, Israel Patent 10,573, 1957

3 G. Hass, H. H. Schroeder and A. F. Turner, F. Opt. Soc. Am., 1956, 46, 31

4 D. J. Close, CSIRO Eng. Sec., Report E.D. 7, Melbourne (June 1962)

5 B. O. Seraphin, "Research Applied to Solar-Thermal Power Systems", Quarterly Progress Report Jan. 1 to March 31, 1974 under NSF/RANN Grant GI-36731X

6 R. C. Langley, "Gold Coatings for Temperature Control in Space Exploration", Gold Bull., 1971, 4, (4), 62

7 R. G. Finch, "Gold in Thick Film Hybrid Microelectronics", Gold Bull., 1972, 5, (2), 26

8 H. M. Fitch, U.S. Patent 2,984,575, 1961

9 H. M. Fitch, U.S. Patent 2,994,614, 1961

10 H. M. Fitch, U.S. Patent 3,163,665, 1964

11 H. M. Fitch, U.S. Patent 3,262,790, 1966

12 R. C. Langley and H. M. Fitch, U.S. Patent 3,313,632, 1967

13 R. C. Langley, U.S. Patent 3,573,970, 1971

14 R. C. Langley, U.S. Patent 3,445,662, 1969

15 R. C. Langley, U.S. Patent 3,363,090, 1968

16 R. C. Langley, U.S. Patent 3,176,678, 1965

17 O. Loebich, "The Optical Properties of Gold", Gold Bull., 1972, 5, (1), 2

18 R. C. Langley, U.S. Patent $3,176,679,1965$

\section{Expanded Metal Dental Reinforcements}

Traditionally reinforcements for dental palates have been fabricated in a 75 per cent gold alloy in the form of gauze woven from 0.005 inch diameter wire. An innovation by Engelhard Industries of London is the supply of such reinforcements in expanded metal. Manufactured by the Expanded Metal Company, London, the newer type of reinforcement provides a more economical product, the greater strength of the expanded metal allowing the palate to be thinner. While two thicknesses of gauze were formerly required for strength, only one piece of expanded metal is necessary, while a further advantage is the absence of frayed edges. It is also cheaper to produce.

Expanded metal is produced from sheet by a continuous shear and press operation. It is easily formed to shape and offers a wider range of strand widths, thicknesses and aperture sizes, so that a mesh can be chosen to suit any individual application.

Other possibilities for the use of gold alloys in this form include applications where their complete resistance to corrosion is required, coupled with their high conductivity and the rapid dissipation of heat characteristic of expanded metal.

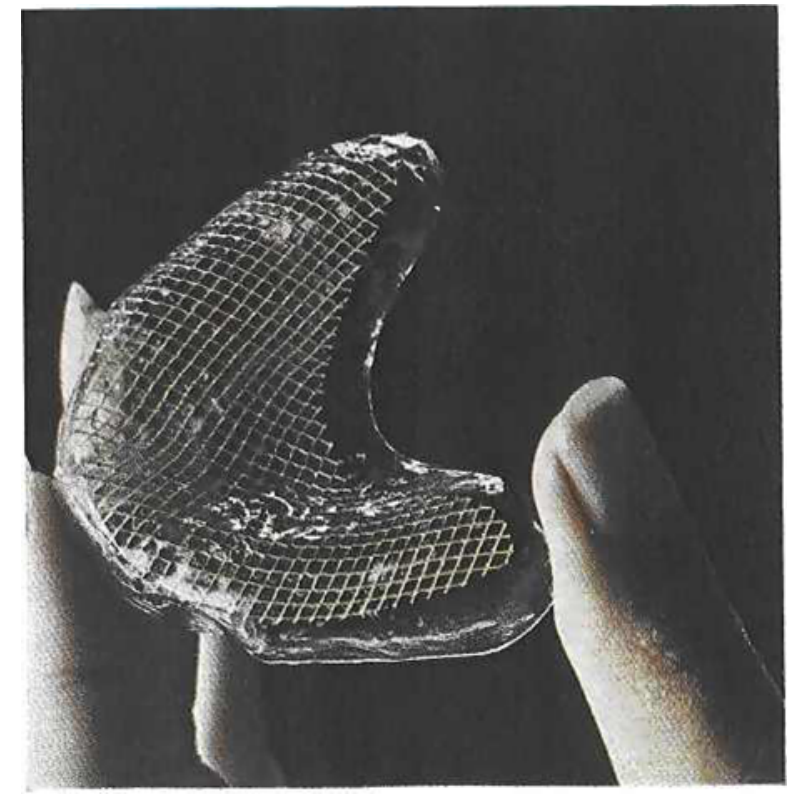

